\title{
Assessment of Nutritional Status of Adolescent College Girls at Rawalpindi (Original Article)
}

\author{
SHAHID A ${ }^{1}$., SIDDIQUI F.R ${ }^{2}$., BHATTI M.A ${ }^{3}$, AHMED M${ }^{4}$., KHAN M.W. ${ }^{5}$ \\ Address for Correspondence: Dr Ayaz Bhatti, HOD Community Medicine Deptt. Islamic International Medical College, \\ Rawalpindi.
}

Objectives: To assess the nutritional status of adolescent college girls by assessing the dietary intake in terms of carbohydrates, proteins, Estimating the hemoglobin levels in the study group and studying the clinical signs of malnutrition with special emphasis to vitamin A, iron and iodine deficiency.

Design of Study: A cross-sectional study.

Settings: Two Post-Graduate women colleges of Rawalpindi.

Study Duration: 9 Months (From Jan 2006 to September 2006).

Materials and Methods: Nutritional status of 508 adolescent girls was assessed with a questionnaire, clinical examination and biochemical estimation (hemoglobin). The data thus collected was analyzed in July 2006 on computer with the help of Statistical Package for Social Sciences (SPSS) and Excel.

Results: Results revealed that $20 \%$ of girls were having BMI $<18.5$, $77 \%$ above $18.5 \%$ and $3 \%$ were obese. $57.09 \%$ of the girls had goiter out of which $52.96 \%$ had palpable goiter and $4.13 \%$ had visible goiter. Pallor conjunctiva was seen in $1 \%$ girls. No clinical signs of Vitamin A deficiency were seen. Biochemical results indicated that $32.87 \%$ of the girls was suffering from Iron deficiency anemia.

Conclusions: Large longitudinal and cross-sectional studies, regarding nutrient consumption, dietary habits and nutritional intervention are required in the adolescent girls. These studies can be thought provoking for the policy maker at the government level. Nutritional education and health promotion can be used as tool to improve the health status of the nation.

Key Words: Adolescent Health, Nutrition, Nutritional Assessment.

\section{Introduction}

The world population is believed to have reached over 6.6 billion, $19 \%$ of world's populations-around 1200 million persons are between 10-19 years of age. This proportion of population faces a series of serious nutritional challenges not only affecting their growth and development but also their livelihood as adults ${ }^{1}$. Yet adolescents remain a largely neglected, difficult-to- measure, and hard-to-reach population, in which the needs of adolescent girls in particular are often ignored. Adolescence is a particularly unique period in life because it is a time of intense physical, psychosocial, and cognitive development. Increased nutritional needs at this juncture relate to the fact that adolescents gain up to $50 \%$ of their adult weight, more than $20 \%$ of their adult height, and $50 \%$ of their adult skeletal mass during this period. Caloric and protein requirements are maximal. Increased physical activity, combined with poor eating habits and other considerations, e.g. menstruation and pregnancy, contribute to accentuating the potential risk for adolescents of poor nutrition.

The main nutrition problems affecting adolescent populations worldwide include under nutrition, Iron deficiency and anemia; Iodine deficiency; Vitamin A deficiency;

Calcium deficiency and other specific nutrient deficiencies like zinc, foliate, and obesity.
The nutrition surveys are part of ongoing projects of all the governments of the world to keep themselves abreast to the latest nutritional situation of their people. This enables them to take corrective measures well in time because timely actions can be fruitful. In Pakistan serial nutrition surveys have been conducted for this purpose in 1956, 1985 and 2001 - 2002 but no attention has been given on the nutrition of the adolescent-a crucial segment of the population.

Like other developing countries of the world, malnutrition remains a major public health problem in Pakistan. The available data shows the major nutritional problems in the country include low birth weight babies due to poor maternal nutrition, protein energy malnutrition and anemia across various groups of population and geographic areas.

The National Nutrition Survey (2001-02) ${ }^{2}$ revealed that among the children of 6-59 months, 38\% were stunted and $13.1 \%$ were wasted. When compared with the NNS (1985$87)^{3}$ figures there has been improvement in the prevalence of underweight (51.5 to $41.5 \%$ ) stunting (46.3 to $31.0 \%$ ) and wasting (15.3 to $11.6 \%)$. Among the non-pregnant women $12.5 \%$ were malnourished $(\mathrm{BMI}<18.5)$. This clearly reflects that rate of malnutrition is high. There has been a decline in stunting and underweight and an almost constant level of wasting over time when compared with the figures 
of (NNS 1985-87). Prevalence of visible goiter among mothers at national level was $12.2 \%$ and mothers residing in rural areas had high prevalence of visible goiter as compared to those living in urban areas. Among pregnant and lactating mothers the prevalence of malnutrition in the country is not better than that in children. The (NNS 1985-87) reported that $34.2 \%$ of pregnant women were severely underweight (BMI less than 18.5).

The Pakistan Socio-Economic Survey (1998-99) ${ }^{3}$ establishes that the nutritional status of children less than 5 years of age had further deteriorated. Prevalence of malnutrition among pregnant and lactating mothers is not better than that in children. Despite an increase in the per capita income during the last two decades, increase in poverty has been observed in the country and this has direct impact on increasing the prevalence of malnutrition.

Continued assessment of nutritional status and monitoring of the micro \& macronutrient deficiencies in population especially adolescent girls is need of the time. The studies like this will help in formulating national nutritional policy and provide the health professionals a frame work for counseling the individual adolescent.

\section{Aim of The Study}

To assess the nutritional status of adolescent college girls by:

1. assessing the dietary intake in terms of carbohydrates, proteins,

2. Estimating the hemoglobin levels in the study group.

3. studying the clinical signs of malnutrition with special emphasis to vitamin A, iron and iodine deficiency.

\section{Materials \& Methods}

Assessment of nutritional status of the adolescent college girls from 17 - 19 years of age. The data was collected from two Post Graduate College for Women located in Rawalpindi. The reason for selecting this area was that population of Rawalpindi apart from locals consists of immigrants from nearby areas like Murree, Attock, Chakwal as well as other parts of the Punjab, and small numbers from other provinces of Pakistan. Therefore, adolescent girls who were studying in these colleges represent all these areas. Hence, the sample was true representative of the population under study. The 508 girls were selected through simple random sampling technique (WHO 1995) ${ }^{4}$, these girls were selected from 5080 adolescent girls which were split into 3 groups i.e. 17 years, 18 years \& 19 years. Inclusion or exclusion criteria were the specific age groups.

In this study socio-demographic profile (age, education \& occupation of parents, family income and size), anthropometric measurements (height, weight and BMI) dietary history (through semi quantitative food frequency for weekly, daily and one time consumption of cereal, meat, milk, egg, pulses, oils, DGLV and fruits) clinical examination to asses the signs of nutritional deficiencies and hemoglobin estimation with Cynmethemoglobin method. For hemo- globin estimation a field laboratory was established at each college during the time of survey. The sample was collected from $1^{\text {st }}$ April to $12^{\text {th }}$ April 2006. The data thus collected was analyzed in July 2006 on computer with the help of Statistical Package for Social Sciences (SPSS) and Excel. Consent was obtained from each subject for participating in the study and for hemoglobin estimation.

The tools and techniques used in this study were:

1. Questionnaire.

2. Clinical Examination.

3. Hemoglobin Estimation.

\section{Results}

\section{Age of the Adolescent Girls}

Out of 508 girls 197 (39.77\%) were 17 year of age, 163 (32.08\%) were 18 year of age and 148 (29.1.3\%) were 19 year of age. Mean height and weight of adolescent girls showed in table 1 .

Table 1: Mean Height and Weight of Adolescent Girls.

\begin{tabular}{|c|c|c|}
\hline $\begin{array}{c}\text { Age Groups } \\
\text { (completed yrs) }\end{array}$ & $\begin{array}{c}\text { Mean Height } \\
\text { (cm) }\end{array}$ & $\begin{array}{c}\text { Mean Weight } \\
\text { (kg) }\end{array}$ \\
\hline 17 & 154 & $\mathbf{4 9}$ \\
\hline 18 & 156 & $\mathbf{5 2}$ \\
\hline $\mathbf{1 9}$ & $\mathbf{1 5 8}$ & $\mathbf{5 4}$ \\
\hline
\end{tabular}

\section{Parent's Education}

The results revealed that almost all the fathers were literate, among them $20.9 \%$ were metric, $28 \%$ were intermediate, $35.6 \%$, and $8.9 \%$ were graduate and post graduate. Literacy rate among the mothers were also high, $1 \%$ were uneducated, $9.8 \%$ were primary, $12.8 \%$ were middle, $41.50 \%$ were metric, $17.5 \%$ were intermediate, $14.6 \%$ graduate, and $2.8 \%$ were post graduate.

\section{Fathers' Profession}

The results revealed that, $1.77 \%$ of the fathers by occupation were laborers, $29.52 \%$ were government servants, $58.26 \%$ were doing private jobs, and $7.28 \%$ were professionals. The average family composition was $6.8 \pm 1.8$ persons per family .Family size ranged from 2 to 13 members.

\section{ANTHROPOMETRY}

\section{Body Mass Index (BMI)}

The Body mass index indicator is based on body weight and height, while age is not included in its measurement. The BMI revealed that $20 \%$ of the girls were underweight (BMI $<18.5$ ), $77 \%$ were within normal limits (BMI >18.5), and $3 \%$ were obese $(\mathrm{BMI}>30)$. The $\mathrm{WHO}$ classification was used for interpretation of the results (Fig. 1). 


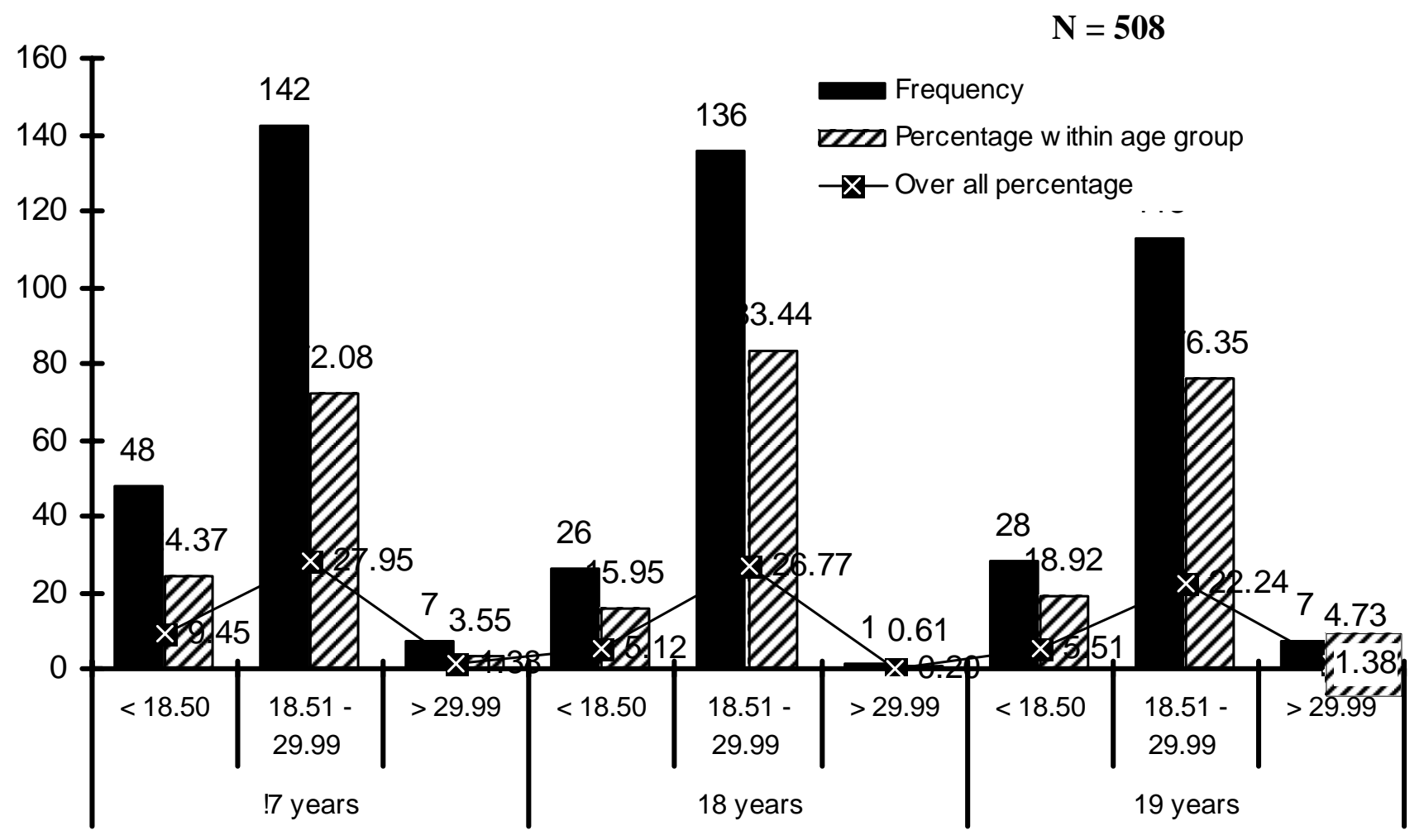

Fig. 1: Frequency and \%age Distribution of Body Mass Index Adolescent Girls.

Table 2: Consumption Frequency of Different Food Items by College Girls.

\begin{tabular}{|l|c|c|c|c|c|}
\hline Food groups & $\begin{array}{c}\text { No of Days } \\
\text { per week }\end{array}$ & $\begin{array}{c}\text { No of times } \\
\text { Per day }\end{array}$ & $\begin{array}{c}\text { One time } \\
\text { Standardized } \\
\text { Portion size (gm) }\end{array}$ & Calories & $\begin{array}{c}\text { Protein } \\
\text { (gm) }\end{array}$ \\
\hline Wheat & 6.47 & 2.26 & 133.0 & 499.0 & $\mathbf{1 9 . 1 3}$ \\
\hline Rice & 2.26 & 1.46 & 323.50 & 631.0 & $\mathbf{1 5 . 0 8}$ \\
\hline Meat / Meat products & 2.41 & 1.40 & 66.70 & 130.5 & $\mathbf{1 2 . 1 3}$ \\
\hline Pulses & 5.23 & 2.43 & 135.60 & 324.2 & $\mathbf{2 9 . 7 8}$ \\
\hline Fats / edible oils & 7.0 & 3.0 & 5.70 & 33.1 & $\mathbf{3 2 . 6}$ \\
\hline Milk / milk products & 2.48 & 1.30 & 178.8 & 173.0 & $\mathbf{7 . 8}$ \\
\hline DGLV & 2.0 & 1.26 & 70.90 & 34.76 & $\mathbf{1 . 3 3}$ \\
\hline Fruits & $\mathbf{4 . 4 2}$ & $\mathbf{1 . 2 2}$ & $\mathbf{1 1 0 . 0}$ & $\mathbf{1 0 4 . 2}$ & $\mathbf{2 . 3}$ \\
\hline
\end{tabular}

\section{Results of the Dietary Survey}

Frequency of consumption of different food items by the girls is shown in (Table 2).

Relationship between age and total caloric intake showed positive correlation $\left(r^{2}=0.097\right)$ between the age groups and total calories consume (Fig. 2).

\section{Use of Iodized Salt}

Iodized salt was used by $50.39 \%$ of the households whereas $49.61 \%$ of the households were not using iodized salt.
D. Clinical Examination for Micronutrient Deficiencies Iodine

Iodine deficiency results in the enlargement of thyroid gland which is termed as goiter. The results revealed that among the girls $57.09 \%$ of the girls had goiter indicating high prevalence rate of iodine deficiency in the girls, among them $52.96 \%$ girls had palpable goiter and $4.13 \%$ had visible goiter (Fig. 3).

Clinically iron deficiency is manifested as pallor conjunctiva, which was seen only in $1 \%$ of the college girls. 


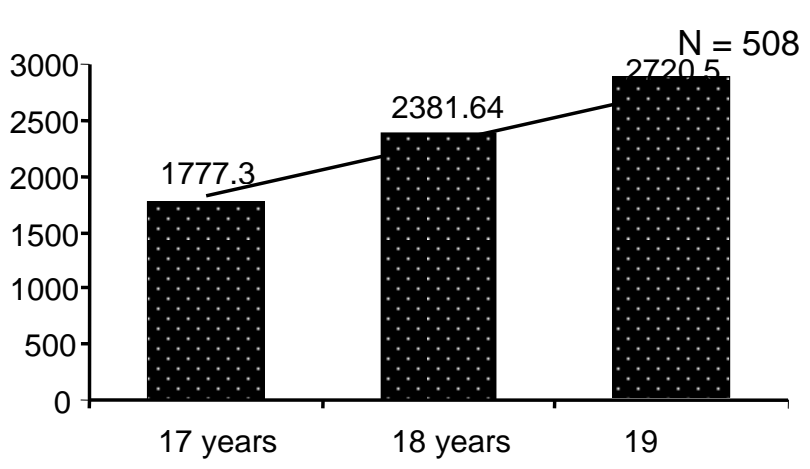

Fig. 2: Relationship between Age and Total Caloric Intake of Adolescent Girls.

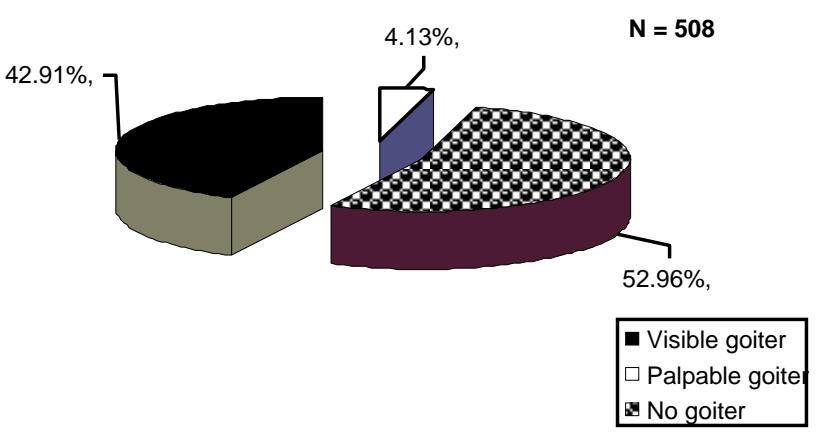

Fig. 3: Prevalence of Goiter in Adolescent Girls.

\section{Vitamin A}

No clinical signs of vitamin A deficiency such as Night blindness, Bitot spots, Keratomalacia and Conjunctival Xerosis were observed in the college girls.

\section{E. Hemoglobin Estimation Hemoglobin (Hb) levels:}

The Biochemical results of the study indicate that $32.87 \%$ of the girls were suffering from iron deficiency anemia and $67.12 \%$ of the girls were not anemic. Anemia was classified as mild, moderate, and severe anemia.

Strong positive correlation $\left(\mathrm{r}^{2}=0.96\right)$ was found between adolescent age groups, caloric intake and hemoglobin, the $\mathrm{Hb}$ level of the girls increased with increased in caloric intake of girls. This relationship between age, caloric intake, and $\mathrm{Hb}$ is shown in (Fig. 4).

\section{Discussion}

The present study revealed that $100 \%$ of the fathers were educated, out of which $97 \%$ were above the primary level. Among the mothers $99 \%$ were educated out of which $89 \%$ were above the primary level. This literacy rate is much higher than national literacy rate of $51.6 \% .^{3 .}$ The reason for high literacy rate can be attributed to the fact that Rawalpindi is an urban area and adjacent to the Capital of Islamic Republic of Pakistan, and thus people have more opportunities and education institutions. The high literacy rate among the mothers is very encouraging, because female literacy plays a key role in improving the health and nutritional status of the families.

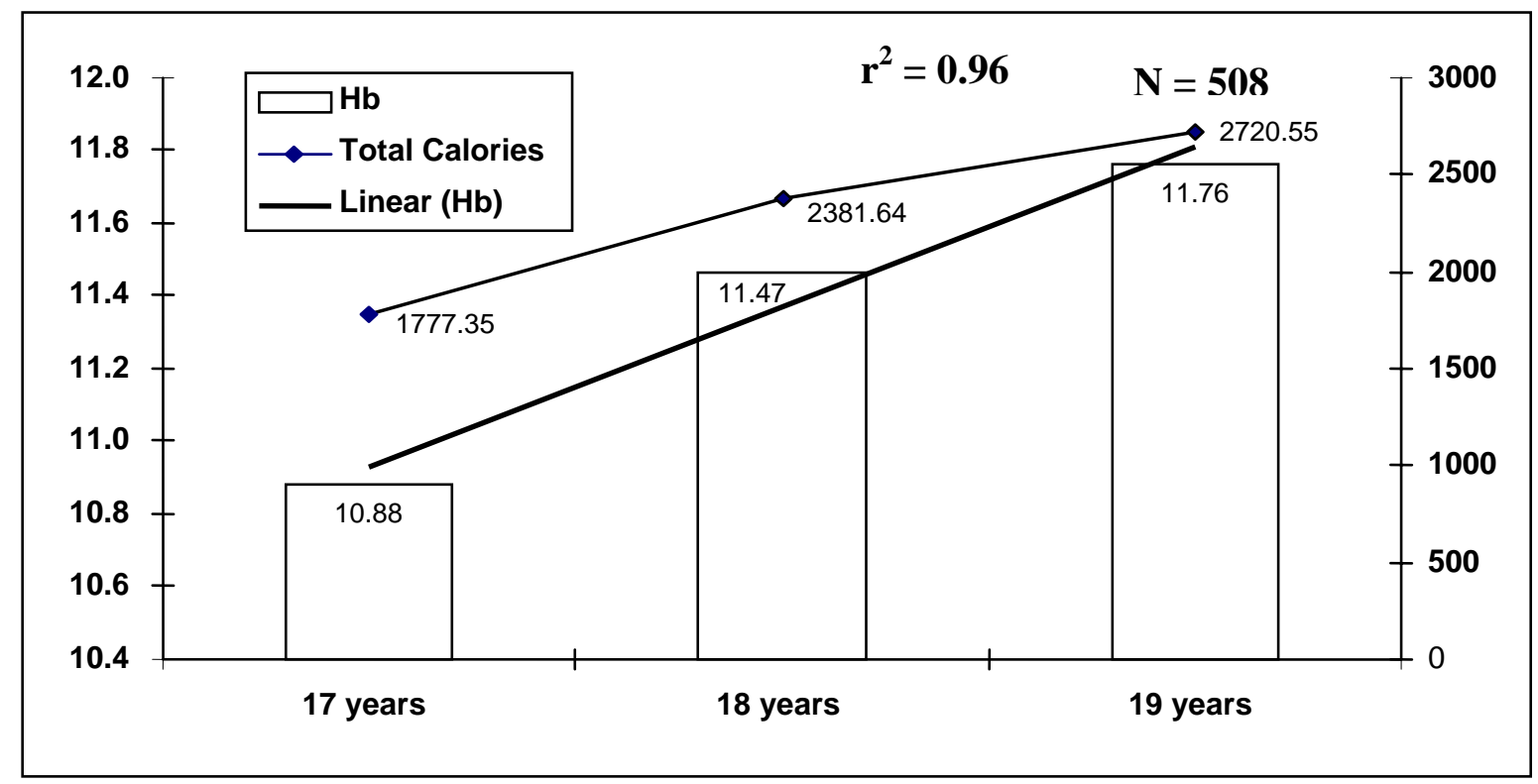

Fig. 4: Correlation between Adolescent Age Group, Caloric Intake and Hemoglo.

Malnutrition was calculated by using BMI, a measure of nutrition through which it was observed that $20 \%$ of the girls were under nourished, 77\% were having normal BMI which revealed that they were well nourished and only $3 \%$ 
were obese. 20-30\% underweight is high prevalence rate and is indicated as a serious situation and needs immediate intervention $^{5}$. 20\% under nourished is slightly higher when compared with the finding of (NNS 2001-02) ${ }^{2}$ which was $12 \%$. The results are still better than Indian, where $51.43 \%$ and $35.5 \%$ adolescent girls were reported to be malnourished. ${ }^{6,7}$ In Bangladesh 59\% adolescent girls were malnourished. A study conducted in Peshawar, Pakistan ${ }^{8}$ thinness was found from 19-21\%. Obesity in the college girls was only $3.0 \%$, which is less than that in developed countries; Three meals per day were taken by $90-95 \%$ of the girls i.e. of Breakfast, Lunch and Dinner. Consumption of chapatti $127.7 \pm 68.2 \mathrm{gm} /$ day is lower than the national consumption of $322 \mathrm{gm} /$ person/day, but girls were consuming rice frequently and in greater quantity which contributed to the over all consumption of cereals which was 450 gm/per person/ day which is even higher than the national consumption of cereals which was $342 \mathrm{gm} /$ person/day. Meat and meat products intake was $65.1 \mathrm{gm} /$ day/person, which was less than the national consumption of meat which was $72 \mathrm{gm} /$ day/ person. Average pulses consumption was $135 \mathrm{gm} /$ day which was 5 times higher than the national consumption of 25 gm/day. Average consumption of milk, was $125 \mathrm{ml} /$ day, DGLV $70 \mathrm{gm} /$ day, $33 \mathrm{gm} /$ day of edible oil, $110 \mathrm{gm} /$ day of fruits, these figures are better than the national consumption figures, which are $90 \mathrm{ml} /$ day, $44 \mathrm{gm} /$ day, 28gm/day and 24 gm/day respectively. ${ }^{2}$

Less consumption of meat and more consumption of pulses were due to the high cost of meat, which a large proportion of population cannot afford. In present study on average in the girls 17-19 years of age the Caloric consumption was $2246 \pm 626$ calories. This was better than the RDA for these girls and close to 2099 calories intake at the national level. ${ }^{2}$ The caloric consumption when seen with specific age group showed that the 17 years old girls were taking on an average $1777 \pm 489$ calories which was $17.74 \%$ less of the RDA. The caloric intake of 18 and 19 year's girls was adequate; hence the overall caloric intake remained adequate. Caloric consumption of 1777 calories is somewhat close to the caloric intake of Indian and American girls ${ }^{9}$, which was $1609.19 \pm 528$ and 1809 calories/day, respectively.

The reasons for better caloric intake were that the study was conducted in the college girls. At this stage girls become more conscious about their dietary intake as they spend most of their time at home availing better opportunity of eating. The other important factor was the mother's education, which contributes significantly and adequately to the nutrition of their daughters. Protein consumption was 121.5 gm/day, which was much better than the national consumption of protein $58 \mathrm{gm} / \mathrm{day}^{2}$. Pulses contributed major portion of proteins, which provides $30 \%$ of the total proteins consumed. Pulses considered low quality proteins due to low content of two essential amino acids. Just $10 \%$ of the total proteins consumed were provided by animal source.
Approximately $5 \%$ of the world population have goiter, out of this $75 \%$ of the population is living in the developing countries, sub-clinical vitamin-A deficiency is considered a problem for at least 251 millions $^{10}$. In the study under discussion, the total goiter rate comes to $57 \%$, which was quite high but reason could be that Rawalpindi is surrounded by hills of Himalayas range and soil may have reduced iodine content. In India the goiter rate is $65.2 \%{ }^{11}$. In Bangladesh it is $47.1 \%^{12}$ and Mongolia $43.3 \%{ }^{13}$. A study conducted in Swat, NWFP a hilly area revealed that $45 \%$ women population were having goiter due to iodine deficiency. Hence, the results of present study were in line with the other studies conducted earlier. Goiter prevalence can be related to the use of iodized salt, as $28.92 \%$ of girls having goiter were not using iodized salt.

No clinical signs of vitamin A deficiency were seen in the study population. Anemia was recognized as the greatest nutritional problem among women as $52 \%$ of non-pregnant women suffer from Anemia (WHO, 1992). The present study reveals that the prevalence of anemia was $32.87 \%$. Many developing countries have the same picture. In India it is $38-72 \%{ }^{14}, 68.8 \%$ in Nepal and $46.6 \%$ in Egypt $^{15}$. The findings of this study were in line with the other studies conducted in other countries and also with the National figures of Pakistan, which were $46 \%{ }^{16}$ (Nutrition Country Paper 1992 and WHO 1996) and 50.9\% (NNS-2001-02).

The cause of anemia in the college girls was low intake of iron foods as meat / meat products and DGLV. Meat and meat products intake was 2 times per week, which was poor and only contributes to $10 \%$ of the total protein intake. Intake of protein in the girls was sufficient, but the major portion of the proteins was having low biological value. The main source of iron for the girls was from cereals (wheat \& rice), but the iron in the cereal food groups is less bio-available to the body because of the high contents of inhibitors i.e. phytate and tenin. A positive correlation was found between age, caloric intake and anemia in this study.

\section{Conclusion}

Nutritional status of the adolescent girls in this study was adequate in terms of caloric intake, through cereals, fruits, vegetables and pulses but was inadequate regarding the intake of milk, meat and meat products. Animal produced products are major contributors of the protein of high biological value; even then the scenario was not so bad when compared with other countries of the developing world. The diet in these girls was not balanced. The major factors leading to poverty were large family size and lack of nutrition education. Large longitudinal and cross-sectional studies, regarding nutrient consumption, dietary habits and nutritional intervention are required in the adolescent girls. These studies can be thought provoking for the policy maker at the government level. Nutritional education and health promotion can be used as tool to improve the health status of the nation. 


\section{References}

1. Cordonnier, D. 1995. Événements quotidiens et bienêtre à l'adolescence. Vers denouvelles stratégies d'éducation pour la santé. Genève. Éd Méd Hyg,

2. National Nutrition Survey, 2001-02. PIDE/UNICEF, Nutrition Section, Planning and Development Division. Government of Pakistan, Islamabad.

3. Economic Survey of Pakistan, 2002-03. Planning and Development Division, Ministry of Finance, Islamabad.

4. Steel, R. G. D. and J. H. Torrie, 1980. Principles and procedures of statistics. McGraw Hill Book Co, Inc. New York.

5. WHO Technical Report Series (854), 1995. Physical Status: The Use and Interpretation of Anthropometry; WHO, Geneva.

6. Singh, N., and C. P. Mishra, 2001. Nutritional status of adolescent girls of a slum community of Varanasi. Indian J Public Health. Oct-Dec; 45 (4): 128-34.

7. Kapoor, G., and S. Aneja, 1992. Nutritional disorders in adolescent girls. Indian Pediatr, 29 (8): 969-73.

8. Din, Z. U., and P. I. Paracha, 2003. Assessment of nutritional status of adolescent boys from public and private schools of Peshawar. Pakistan J Med Res Sep; 42 (3): 129-33.

9. USDA, 1997. US Department of Agriculture, Agricultural Research Service, Pyramid Serving Data: Results from USDA's 1995 and 1996 Continuing Survey of Food Intakes by Individuals, December 1997.
10. Stephenson, L. S., M. C. Latham, and E. A. Ottesen, 2000. Global malnutrition. Parasitology. 121 Suppl: S522.

11. Dodd, N. S., and M. L. Godhia, 1992. Prevalence of iodine deficiency disorders in adolescents. Indian $\mathrm{J}$ Pediatr Sep-Oct; 59 (5): 585-91.

12. Yusuf, H. K., S. Quazi, and M. R. Kahn, 1996. Iodine deficiency disorders in Bangladesh. Indian J. Pediatr Jan-Feb; 63 (1): 105-10.

13. Fuse, Y., T. Igari, and C. Yamada, 2003. Epidemiological survey of thyroid volume and iodine intake in schoolchildren, postpartum women and neonates living in Ulaan Baatar. Clin Endocrinol (Oxf). Sep; 59 (3): 298-306.

14. Choudhury, P., and S. Vir, 1994. Prevention and strategies for control of iron deficiency anemia. In: Nutrition in children - Developing Country Concerns. Eds. Sachdev HPS, Choudhury P. Cambridge Press, New Delhi. Pp 492-524.

15. El-Sahn, F., S. Sallam, and A. Mandil, 2000. Anemia among Egyptian adolescents: prevalence and determinants. East Mediterr Health J Sep-Nov; 6 (5-6): 101725.

16. Nutrition Country Paper, 1992. Joint FAO/WHO Conference on Nutrition. Nutrition Section, Planning and Development Division; Government of Pakistan, Islamabad. 